\title{
Smoking Cessation Among Women with and at Risk for HIV: Are They Quitting?
}

\author{
David Goldberg, MD' ${ }^{7}$, Kathleen M. Weber, BSN², Jennifer Orsi, MPH ${ }^{3}$, Nancy A. Hessol, MSPH \\ Gypsyamber D'Souza, $P h D^{5}$, D. Heather Watts, MD ${ }^{6}$, Rebecca Schwartz, PhD', \\ Chenglong Liu, MD ${ }^{8}$, Marshall Glesby, MD ${ }^{9}$, Pamela Burian, $P A-C^{10}$, and Mardge H. Cohen, $\mathrm{MD}^{7}$
}

\begin{abstract}
'Division of General Medicine, John H. Stroger, Jr Hospital of Cook County and Rush University, Chicago, IL, USA; ${ }^{2}$ Ruth M. Rothstein CORE Center of Cook County, Chicago, IL, USA; ${ }^{3}$ Sinai Urban Health Institute, Chicago, IL, USA; ${ }^{4}$ University of California, San Francisco, CA, USA; ${ }^{5}$ Johns Hopkins Bloomberg School of Public Health, Baltimore, MD, USA; ${ }^{6}$ Eunice Kennedy Shriver National Institute of Child Health and Human Development, Bethesda, MD, USA; ${ }^{7}$ State University of New York Health Science Center at Brooklyn, NY, NY, USA; ${ }^{8}$ Georgetown University School of Medicine, Washington, DC, USA; ${ }^{9}$ Weill Medical College of Cornell University, NY, NY, USA; ${ }^{10}$ University of Southern California, Los Angeles, CA, USA.
\end{abstract}

BACKGROUND: Cigarette smoking is an important risk factor for adverse health events in HIV-infected populations. While recent US population-wide surveys report annual sustained smoking cessation rates of $3.4-8.5 \%$, prospective data are lacking on cessation rates for HIVinfected smokers.

OBJECTIVE: To determine the sustained tobacco cessation rate and predictors of cessation among women with or at risk for HIV infection.

DESIGN: Prospective cohort study.

PARTICIPANTS: A total of 747 women (537 HIVinfected and 210 HIV-uninfected) who reported smoking at enrollment (1994-1995) in the Women's Interagency HIV Study (WIHS) and remained in follow-up after 10 years. The participants were mostly minority $(61 \%$ non-Hispanic Blacks and 22\% Hispanics) and low income $(68 \%$ with reported annual incomes of less than or equal to $\$ 12,000)$.

MEASUREMENTS AND MAIN RESULTS: The primary outcome was defined as greater than 12 months continuous cessation at year 10. Multivariate logistic regression was used to identify independent baseline predictors of subsequent tobacco cessation. A total of 121 (16\%) women reported tobacco cessation at year 10 (annual sustained cessation rate of $1.8 \%$, 95\% CI $1.6-$ $2.1 \%$ ). Annual sustained cessation rates were $1.8 \%$ among both HIV-positive and HIV-negative women ( $\mathrm{p}=$ 0.82). In multivariate analysis, the odds of tobacco cessation were significantly higher in women with more years of education ( $\mathrm{p}$ trend $=0.02$ ) and of Hispanic origin $(\mathrm{OR}=1.87,95 \% \mathrm{CI}=1.4-2.9)$ compared to Black women. Cessation was significantly lower in current or former illicit drug users $(\mathrm{OR}=0.4295 \% \mathrm{CI}=0.24-0.74$ and $\mathrm{OR}=$ 0.65, 95\% CI=0.49-0.86, respectively, p trend=0.03) and women reporting a higher number of cigarettes per day at baseline (p trend $<0.001)$.

This analysis was previously presented at the XVII International AIDS Conference, Mexico City, August 2008.

Received February 23, 2009

Revised September 15, 2009

Accepted September 25, 2009

Published online November 17, 2009
CONCLUSIONS: HIV-infected and at-risk women in this cohort have lower smoking cessation rates than the general population. Given the high prevalence of smoking, the high risk of adverse health events from smoking, and low rates of cessation, it is imperative that we increase efforts and overcome barriers to help these women quit smoking.

KEY WORDS: smoking cessation; HIV/AIDS; clinical epidemiology; vulnerable populations.

$\mathrm{J}$ Gen Intern Med 25(1):39-44

DOI: $10.1007 / \mathrm{s} 11606-009-1150-2$

(c) Society of General Internal Medicine 2009

\section{INTRODUCTION}

Smoking is common among HIV-infected people, with surveys showing consistent smoking rates above $45 \%$ and as high as $74 \% .{ }^{1-3}$ The widespread use of anti-retroviral therapies has resulted in a dramatic reduction of HIV-related morbidity and mortality. ${ }^{4,5}$ Improvements in the care and longevity of persons with HIV have increased the attention on smoking cessation for HIV-infected individuals. ${ }^{1,2,6}$

There are overlapping hazards of HIV infection, its treatment, and smoking that draw attention to smoking as a modifiable risk factor. Smoking has been reported to be independently associated with adverse HIV-related outcomes in the context of HAART, including the development of clinical AIDS, lower CD4 counts, a trend toward higher viral loads ${ }^{7}$, and poorer health-related quality of life. ${ }^{8,9}$ The cardiovascular risk of smoking is important since HIV-infected individuals may have more extensive sub-clinical atherosclerosis compared to HIV-uninfected individuals, ${ }^{10}$ and protease inhibitors may confer cardiovascular risk. ${ }^{11,12}$ Initial studies reported increased risk of lung cancer among HIV-infected individuals independent of tobacco use $\mathrm{e}^{13}$ and earlier diagnosis of latestage lung cancers in HIV-infected individuals with lower smoking exposure. ${ }^{14}$ HIV infection is an independent risk factor for chronic obstructive pulmonary disease. ${ }^{15}$

While smoking rates are high and the risk of smokingrelated morbidity is increased, little is known about smoking cessation in HIV-infected individuals. In surveys among HIV- 
infected individuals who ever smoked, 22\%-39\% were abstinent at the time they were surveyed ${ }^{9,16-18}$ compared to $52 \%$ in the general population. ${ }^{19}$ These cross-sectional data, while suggestive of less cessation, do not adequately assess cessation rates of HIV-infected smokers.

Published estimates of annual sustained cessation determined from population-based US surveys range from 3.4 to $8.5 \%$ per year. ${ }^{20,21}$ During the decade of the 1990 s, data from the Tobacco Use Supplement to the Current Population Survey showed that the annual rate of 12-month sustained smoking cessation among non-Hispanic Whites was 3.4\%. ${ }^{20}$ A more recent analysis of the 2003 Current Population Survey showed 6-month population-wide sustained cessation ranging from 5.0 to $8.5 \%$ among various age groupings. ${ }^{21}$

The Women's Interagency HIV Study (WIHS) is a longitudinal cohort study of women with and at risk for HIV. As smoking status is tracked in WIHS, it provides a unique opportunity to determine the annual rate of sustained smoking cessation. Similar to other cohorts of HIV-infected persons, the baseline rate of smoking among the HIV-infected women in WIHS was $56 \%$. The rate of smoking among the HIV-uninfected women in WIHS was $63 \%{ }^{22}$ The high rate of smoking among both the HIV-infected and HIV-uninfected women in WIHS likely reflects the presence of life stressors including poverty, substance use, and depression. ${ }^{23,24}$

In this study, we describe the annual rate of sustained tobacco cessation among surviving women in WIHS who smoked at baseline and were followed for 10 years. This study aims to compare smoking cessation rates among women with or at risk for HIV infection to the US population. We also describe baseline demographic, psychosocial, and smokingrelated predictors of sustained cessation for women in WIHS.

\section{METHODS}

The overall aim of the Women's Interagency HIV Study (WIHS) is to examine HIV disease progression in women, including how clinical and psychosocial variables are associated with HIV-related disease outcomes. In 1994 and 1995, WIHS recruited 2,626 women with confirmed HIV sero-status: 2,058 were HIV-infected and 568 were HIV-uninfected. The participants were recruited from HIV treatment programs, drug treatment programs, HIV testing sites, community outreach, and referral from participants. The study methods were described previously. ${ }^{23}$ The Institutional Review Boards of the six participating centers approved all study protocols and participants completed written informed consent at baseline and annually.

At the time of enrollment, participants in WIHS were at least 13 years old, agreed to testing and counseling for HIV infection, spoke English or Spanish, and completed the baseline assessments. The baseline assessment included questionnaires of demographics, physical and psychological health status, sexual behavior, health care utilization, and substance and tobacco use. Each semi-annual follow-up visit included similar assessments, and participants received monetary compensation at each visit. At baseline, a current smoker included women who responded "Yes" to the question "Do you currently smoke?" and reported a lifetime history of smoking at least 100 cigarettes. At follow-up study visits, women who reported smoking at prior interviews and not smoking at the current interview were questioned to determine the month and year of their last cigarette.

The primary outcome of sustained cigarette smoking cessation is defined as greater than 12 months of self-reported continuous cessation at year 10 . The average annual rate of sustained cessation was calculated by dividing the rate of cessation at year 10 by 9 , reflecting the 9 years of observation when the cessation could be initiated. In unadjusted analyses of baseline predictors of cessation, we used chi-square and Mantel-Haenzel chi-square tests for nominal and ordinal categorical predictors, respectively. We conducted significance testing via chi-square to examine pairwise differences between ethnic/racial groups. The p-trend for ordinal variables with three or more categories was calculated using the MantelHaenszel chi-square test for trend statistic. Predictors with a $\mathrm{p}$-value of $<0.10$ in unadjusted analyses were included in a backward stepwise multivariate logistic regression model to identify variables that remained significant $(\mathrm{p}<0.05)$ independent predictors of sustained tobacco cessation.

\section{RESULTS}

The smoking status at the time of the year 10 interview was available for 747 (50\%) of 1,503 baseline smokers. Baseline smokers no longer in follow-up at year $10(n=756)$ included $514(68 \%)$ women who dropped out of the study immediately after the baseline visit, $14(2 \%)$ women who had only one incomplete follow-up interview without smoking data beyond baseline, $134(18 \%)$ women who died prior to the year-10 interview, and $94(12 \%)$ surviving women remaining in the study who did not have a year-10 assessment.

The baseline characteristics of the 747 women included in this study are shown in Table 1 . The mean and median age was 36 . The majority were HIV-infected (74\%), non-Hispanic Black (61\%), unemployed (83\%), and with reported annual incomes of less than or equal to $\$ 12,000$ (68\%). Depressive symptoms (Center for Epidemiologic Studies; depression scores 16, 56\%) and current $(41 \%)$ or former $(43 \%)$ use of crack, cocaine, or heroin were common. The majority had insurance (77\%), most of the insured had Medicaid or Medical (81\%), while fewer had private insurance (14\%) or Medicare (4\%).

Compared to the 756 baseline smokers not included in the analysis, the women in our study were more likely HIVuninfected ( $28 \%$ vs. $20 \%, \mathrm{p}<0.001$ ), younger (median years of age at baseline 36 vs. $38, \mathrm{p}<0.001)$, with stable housing $(71 \%$ vs. $65 \%, \mathrm{p}<0.05$ ), employed ( $17 \%$ vs. $12 \%, \mathrm{p}=0.01$ ), smoked for fewer years (median years smoked at baseline 17 vs. $20, \mathrm{p}<$ 0.001 ), lighter smokers ( $\leq 10$ cigarettes per day, $59 \%$ vs. $53 \%$, $\mathrm{p}=<0.05)$, and were less likely non-Hispanic White (14\% vs. $20 \%, \mathrm{p}<0.05$ ) than non-Hispanic Black or Hispanic.

At the year-10 follow-up interviews, 121 (16\%) women reported smoking cessation of greater than 12 months for an average annual sustained cessation rate of $1.8 \%$ (95\% CI 1.6$2.1 \%$ ) per year. At the year-10 interview, an additional $8.8 \%$ of women reported short-term cessation including 12 (1.6\%) women who reported quitting smoking for less than 1 month, $26(3.5 \%)$ women who quit for 1-6 months, and $28(3.7 \%)$ women who quit for 6-12 months. The estimated average annual rate of smoking cessation for 6 months or more $(\mathrm{n}=$ 149) was $2.2 \%$ (95\% CI 1.9-2.5). 
Table 1. Baseline Characteristics and Frequency of Sustained Tobacco Cessation Among Women Who Reported Current Tobacco Use at WIHS Baseline and Remained in Study Follow-Up After 10 Years

\begin{tabular}{|c|c|c|c|c|c|}
\hline \multicolumn{2}{|l|}{ Baseline characteristics } & \multirow{2}{*}{$\begin{array}{l}\text { N (\%) at } \\
\text { Baseline } \\
747(100)\end{array}$} & \multirow{2}{*}{$\begin{array}{l}\begin{array}{l}\% \text { Reporting } \\
\text { tobacco cessation }\end{array} \\
16\end{array}$} & \multirow{2}{*}{$\begin{array}{l}\begin{array}{l}\text { \% Annual cessation } \\
(95 \% \mathrm{Cl})\end{array} \\
1.8(1.6-2.1)\end{array}$} & \multirow[t]{2}{*}{$\begin{array}{l}\text { Unadjusted } \\
\text { OR }(95 \% \mathrm{Cl})\end{array}$} \\
\hline Total & & & & & \\
\hline \multirow[t]{6}{*}{ Study center } & Washington DC & $90(12)$ & 12 & $1.3(0.6-2.1)$ & 1.00 \\
\hline & Bronx & $195(26)$ & 16 & $1.8(1.2-2.4)$ & $1.41(0.68-2.94)$ \\
\hline & Brooklyn & $121(16)$ & 14 & $1.6(0.9-2.2)$ & $1.17(0.52-2.65)$ \\
\hline & Los Angeles & $102(14)$ & 24 & $2.7(1.7-3.5)$ & $2.21(1.01-4.82)$ \\
\hline & San Francisco & $139(19)$ & 14 & $1.6(0.9-2.2)$ & $1.14(0.51-2.52)$ \\
\hline & Chicago & $100(13)$ & 18 & $2.0(1.2-2.8)$ & $1.58(0.70-3.55)$ \\
\hline \multirow[t]{2}{*}{ HIV status } & Infected & $537(74)$ & 16 & $1.8(1.5-2.2)$ & 1.00 \\
\hline & Uninfected & $210(26)$ & 16 & $1.8(1.2-2.3)$ & $1.05(0.68-1.63)$ \\
\hline \multirow[t]{3}{*}{ Age (years) } & $18-30$ & $156(21)$ & 16 & $1.8(1.1-2.4)$ & 1.00 \\
\hline & $31-40$ & $378(51)$ & 18 & $2.0(1.5-2.4)$ & $0.90(0.68-1.19)$ \\
\hline & $41-62$ & $213(29)$ & 14 & $1.6(1.0-2.0)$ & $\begin{array}{l}0.81(0.46-1.41) \\
p \text { trend }=0.46\end{array}$ \\
\hline \multirow[t]{3}{*}{ Ethnicity and race } & Non-Hispanic Black & $456(61)$ & 13 & $1.4(1.1-1.8)$ & 1.00 \\
\hline & Non-Hispanic White & $108(14)$ & 19 & $2.1(1.2-2.9)$ & $1.47(0.85-2.57)$ \\
\hline & Hispanic & $165(22)$ & 22 & $2.4(1.8-3.2)$ & $1.87(1.19-2.95)$ \\
\hline \multirow[t]{3}{*}{ Education level } & Less than high school & $304(41)$ & 13 & $1.4(1.0-1.8)$ & 1.00 \\
\hline & High school graduate & $244(33)$ & 17 & $1.9(1.3-2.4)$ & $1.33(1.05-1.69)$ \\
\hline & Beyond high school & $199(27)$ & 21 & $2.3(1.7-2.9)$ & $\begin{array}{l}1.76(1.09-2.85) \\
p \text { trend }=0.02\end{array}$ \\
\hline \multirow[t]{3}{*}{ Marital status } & $\begin{array}{l}\text { Separated/divorced/ } \\
\text { widowed }\end{array}$ & $206(28)$ & 17 & $1.9(1.3-2.5)$ & 1.00 \\
\hline & Married/cohabitating & $280(37)$ & 17 & $1.9(1.4-2.4)$ & $1.01(0.63-1.63)$ \\
\hline & Single/never married & $253(34)$ & 15 & $1.7(1.1-2.1)$ & $0.84(0.51-1.39)$ \\
\hline \multirow[t]{2}{*}{ Residential housing } & Unstable & $216(29)$ & 13 & $1.4(1.0-2.0)$ & 1.00 \\
\hline & Stable & $531(71)$ & 17 & $1.9(1.6-2.3)$ & $1.35(0.86-2.12)$ \\
\hline \multirow[t]{2}{*}{ Employment status } & Unemployed & $621(83)$ & 16 & $1.8(1.4-2.1)$ & 1.00 \\
\hline & Employed & $125(17)$ & 19 & $2.1(1.4-2.9)$ & $1.28(0.78-2.11)$ \\
\hline \multirow{2}{*}{ Health insurance status } & Uninsured & $167(22)$ & 13 & $1.4(0.8-2.0)$ & 1.00 \\
\hline & Insured & $575(77)$ & 17 & $1.9(1.6-2.3)$ & $1.46(0.88-2.43)$ \\
\hline \multirow[t]{2}{*}{ Income } & $\leq \mathbf{\$} 12,000$ & $505(68)$ & 15 & $1.7(1.4-2.1)$ & 1.00 \\
\hline & $>\$ 12,000$ & $203(27)$ & 17 & $1.9(1.3-2.4)$ & $1.10(0.71-1.71)$ \\
\hline \multirow[t]{2}{*}{ Having a usual source of medical care } & No & $108(15)$ & 13 & $1.4(0.7-2.1)$ & 1.00 \\
\hline & Yes & $634(85)$ & 17 & $1.9(1.6-2.2)$ & $1.36(0.75-2.48)$ \\
\hline \multirow[t]{2}{*}{ Hospitalized in past 6 months } & No & $600(80)$ & 17 & $1.9(1.6-2.2)$ & 1.00 \\
\hline & Yes & $146(20)$ & 13 & $1.4(0.8-2.1)$ & $0.73(0.43-1.04)$ \\
\hline \multirow[t]{2}{*}{ CESD score } & $<16$ & $310(41)$ & 19 & $2.1(1.7-2.6)$ & 1.00 \\
\hline & $\geq 16$ & $422(56)$ & 14 & $1.6(1.2-2.0)$ & $0.70(0.48-1.04)$ \\
\hline Heavy alcohol use & Never & $282(38)$ & 18 & $2.0(1.5-2.6)$ & 1.00 \\
\hline & Former & $351(47)$ & 15 & $1.7(1.3-2.1)$ & $0.82(0.61-1.10)$ \\
\hline & Current & $97(13)$ & 13 & $1.4(0.7-2.2)$ & $\begin{array}{l}0.67(0.37-1.22) \\
p \text { trend }=0.19\end{array}$ \\
\hline Marijuana use & Never & $117(16)$ & 17 & $1.9(1.1-2.7)$ & 1.00 \\
\hline & Former & $394(53)$ & 16 & $1.8(1.4-2.2)$ & $0.97(0.73-1.30)$ \\
\hline & Current & $236(32)$ & 16 & $1.8(1.3-2.3)$ & $\begin{array}{l}0.95(0.53-1.69) \\
p \text { trend }=0.85\end{array}$ \\
\hline Crack, cocaine, or heroin use & Never & $118(16)$ & 26 & $2.9(2.0-3.8)$ & 1.00 \\
\hline & Former & $319(43)$ & 18 & $2.0(1.5-2.5)$ & $0.58(0.44-0.76)$ \\
\hline & Current & $310(41)$ & 11 & $1.2(0.8-1.6)$ & $\begin{array}{l}0.33(0.19-0.57) \\
p \text { trend }<0.001\end{array}$ \\
\hline IV drugs use & Never & $378(51)$ & 17 & $1.9(1.5-2.4)$ & 1.00 \\
\hline & Former & $260(35)$ & 17 & $1.9(1.4-2.4)$ & $0.80(0.60-1.06)$ \\
\hline & Current & $109(15)$ & 10 & $1.1(0.5-1.8)$ & $\begin{array}{l}0.64(0.36-1.12) \\
p \text { trend }=0.12\end{array}$ \\
\hline Average number of cigarettes/day & $\leq 10$ & $443(59)$ & 20 & $2.2(1.8-2.6)$ & 1.00 \\
\hline & $11-20$ & $247(33)$ & 12 & $1.3(0.9-1.8)$ & $0.51(0.35-0.74)$ \\
\hline & $\geq 20$ & $56(8)$ & 5 & $0.6(0.0-1.3)$ & $\begin{array}{l}0.26(0.12-0.54) \\
p \text { trend }=0.003\end{array}$ \\
\hline Number of years since beginning smoking & $0-5$ & $78(10)$ & 27 & $3.0(1.9-4.1)$ & 1.00 \\
\hline & $6-10$ & $107(14)$ & 22 & $2.4(1.6-3.4)$ & $0.81(0.71-0.92)$ \\
\hline & $11-15$ & $152(20)$ & 15 & $1.7(1.0-2.3)$ & $0.65(0.51-0.84)$ \\
\hline & $16-20$ & $170(23)$ & 12 & $1.3(0.8-1.9)$ & $0.53(0.36-0.77)$ \\
\hline & $21-25$ & $122(16)$ & 17 & $1.9(1.2-2.7)$ & $0.43(0.26-0.71)$ \\
\hline & $\geq 26$ & $118(16)$ & 9 & $1.0(0.5-1.6)$ & $\begin{array}{l}0.34(0.18-0.65) \\
p \text { trend }=0.001\end{array}$ \\
\hline
\end{tabular}


Initiation of 12-month sustained cessation occurred throughout the 9 years of observation; 58 women reporting initiation of cessation during years 1-4 of the study, with 7 quitting during year 5 , and 55 quitting during years $6-9$. The timeframe of initiation of cessation was similar among HIVinfected and HIV-uninfected women (data not shown).

In the unadjusted analysis (Table 1), women from the Los Angeles center were more likely to quit smoking compared to women from the Washington DC site (OR=2.21, 95\% CI $1.01-$ 4.82), reflecting the extremes of the $1.3 \%$ to $2.7 \%$ in annual cessation rates across the study centers. In pairwise comparisons of Black, Hispanic, and White women, only Hispanic women were more likely to quit using tobacco compared to Black women $(\mathrm{OR}=1.87$, 95\% CI 1.19-2.95). Women with education beyond high school were more likely to quit $(\mathrm{OR}=$ $1.76,95 \%$ CI 1.09-2.85), as were high school graduates (OR= 1.33, 95\% CI 1.05-1.69), when compared to women without a high school degree. There was a gradient of increased cessation across the categories of increasing education ( $\mathrm{p}$-trend=0.02). Tobacco cessation was lower in women with depressive symptoms $(\mathrm{OR}=0.70,95 \%$ CI 0.48-1.04). Cessation was not associated with alcohol or marijuana use; however, it was lower in those who reported current use of other illicit drugs $(\mathrm{OR}=0.33$, 95\% CI 0.19-0.57) or former use (OR=0.58, 95\% CI 0.44-0.76) compared to never users. Tobacco cessation decreased significantly across the categories of never, former, and current illicit drug use ( $p$-trend<0.001). Cessation decreased with increasing number of cigarettes smoked per day (p-trend=0.003) and with increasing years of smoking ( $\mathrm{p}$-trend $=0.001)$.

HIV serostatus did not predict cessation. Being married, being employed, having health insurance, or having a usual source of medical care was not associated with odds of cessation.

In adjusted analyses (Table 2), Hispanic women were more likely to have sustained cessation than non-Hispanic Blacks $(\mathrm{OR}=2.07$, 95\% CI 1.28-3.35). Women with more education were more likely to quit smoking $(\mathrm{p}$-trend $=0.02)$. Current $(\mathrm{OR}=$

Table 2. Baseline Characteristics Associated with Tobacco Cessation in Multivariate Analysis of 10-Year Follow-Up Among HIV-Infected and HIV-Uninfected Smokers in the WIHS

\begin{tabular}{|c|c|c|c|}
\hline $\begin{array}{l}\text { Baseline } \\
\text { characteristics }\end{array}$ & $\begin{array}{l}\text { Adjusted } \\
\text { odds ratio }\end{array}$ & $95 \% \mathrm{Cl}$ & $\begin{array}{l}P \text { for } \\
\text { trend }\end{array}$ \\
\hline \multicolumn{4}{|l|}{ Ethnicity and race } \\
\hline Non-Hispanic Black & 1.00 & & \\
\hline Non-Hispanic White & 1.53 & $0.85-2.75$ & \\
\hline Hispanic & 2.07 & $1.28-3.35$ & \\
\hline \multicolumn{4}{|l|}{ Education } \\
\hline Less than high school & 1.00 & & \\
\hline High school graduate & 1.37 & $1.06-1.76$ & 0.02 \\
\hline Beyond high school & 1.87 & $1.13-3.12$ & \\
\hline \multicolumn{4}{|c|}{ Crack/cocaine/heroin use } \\
\hline Never & 1.00 & & \\
\hline Former & 0.65 & $0.49-0.86$ & 0.003 \\
\hline Current & 0.43 & $0.24-0.74$ & \\
\hline \multicolumn{4}{|l|}{ Cigarettes smoked/day } \\
\hline$\leq 10$ & 1.00 & & \\
\hline $11-20$ & 0.50 & $0.34-0.74$ & $<0.001$ \\
\hline$>20$ & 0.25 & $0.12-0.55$ & \\
\hline
\end{tabular}

Variables included in the multivariate model included study center; ethnicity; education; CES-D score; crack, cocaine, or heroin use; average number of cigarettes/day; and number of years since beginning smoking
0.43 95\% CI=0.24-0.75) and former (OR=0.65, 95\% CI 0.49 0.86) users of crack, cocaine, or heroin and those smoking more cigarettes daily ( $\mathrm{p}$-trend $<0.001$ for increasing number of cigarettes) were significantly less likely to quit smoking compared to those who never used these substances or who smoked fewer cigarettes each day. The study center, depressive symptoms, and years of tobacco smoking were not associated with cessation in multivariate analyses.

\section{DISCUSSION}

Our results demonstrate that the cessation rate among women in WIHS was lower than in US population-based studies. NonHispanic Blacks, users of crack, cocaine, or heroin, women with less education, and women smoking more cigarettes on a daily basis were less likely to quit smoking. There were similar rates of sustained smoking cessation among HIV-infected and at-risk HIV-uninfected women.

We used 12 months of tobacco cessation as our primary outcome; this duration of cessation has been recommended as a stringent criterion approximating lifelong abstinence. ${ }^{25}$ This recommendation is based upon data from the California Tobacco Survey. Former smokers identified at a baseline interview were re-interviewed after 18 months. Those who reported duration of cessation at the baseline interview of at least 12 months and as long as more than 10 years had a likelihood of $98 \%$ for the subsequent status of cessation (95\% continuous and $3 \%$ with relapse and subsequent quit), while cessation less than 12 months had a likelihood of $66 \%$ for the subsequent status of cessation ( $42 \%$ continuous cessation and $24 \%$ with relapse and subsequent quit). ${ }^{26}$

While smoking prevalence is regularly tracked, ${ }^{19}$ population-based cessation is infrequently reported. There are two recent publications describing US population-based cessation rates. Messer ${ }^{20}$ analyzed four waves of the Tobacco Use Supplement of the Current Population Survey between 1992 and 2002. The analysis, restricted to non-Hispanic Whites aged 20 to 64 years, reported 12-month sustained cessation. The average annual cessation rate was 3.4\%. Overall there was increasing cessation during the 1990s with the most pronounced acceleration among young smokers. The cessation rates in California, New York, and New Jersey were higher (3.6 to $4.7 \%$ per year) compared to the tobacco growing states (Kentucky, Tennessee, North Carolina, South Carolina, Virginia, and Georgia) (2.8 to $4.2 \%$ per year). Gender-specific rates were not reported. The rates of cessation in the WIHS cohort, applying a similar definition of sustained cessation during this largely overlapping time period, were lower overall (1.8\%) for non-Hispanic Whites $(2.1 \%)$, and for the California and New York centers (1.6 to $2.7 \%$ ).

In a second study, Messer $^{21}$ reported 6-month sustained cessation rates in the 2003 Current Population Survey. This analysis of 18 to 64 year olds included all race and ethnic groups. It reported cessation by age, with rates of $8.5 \%, 7.0 \%$, $5.0 \%$, and $5.1 \%$ for the age groups of $18-24,25-34,35-49$, and 50-64, respectively. Women (1.16), African Americans (0.63), and Hispanics (0.86) had non-significant adjusted odds ratios of cessation. In WIHS, the rate of 6-month sustained cessation was lower at $2.2 \%$.

While several predictors of cessation were identified in this study, cessation rates were low even among those identified as 
likely to quit, including Hispanic women (2.4\%), women with more than high school education $(2.3 \%)$, and those without crack, cocaine, or heroin use $(2.9 \%)$. In our study, HIV status did not predict cessation, likely due to the similar sociodemographic characteristics of the HIV-infected and HIVuninfected women in WIHS. It appeared that the rate of initiation of the sustained cessation among HIV-infected women was not different during the pre-HAART and early HAART eras. Having a usual source of medical care did not predict cessation.

The low rates of sustained cessation add support to calls for increased attention to smoking cessation services in medical care settings for women with HIV and at risk for HIV. ${ }^{1,2,6}$ For this service development, we should consider how gender, race/ethnicity, and social class influence smoking cessation, ${ }^{27-29}$ including knowledge of cessation benefits, ${ }^{24}$ social and environmental support for cessation, ${ }^{30}$ and awareness of and access to integrated counseling and pharmacotherapy. ${ }^{31,32}$ In addition, we believe that the clinical implication of drug use warrants consideration as a predictor of poor cessation outcomes. Histories of substance use are common among individuals who smoke and are HIV-infected or at risk (in this study there were $84 \%$ with current or former illicit drug use). There is an emerging consensus that smoking cessation programs for individuals in substance use treatment or recovery are effective and may enhance substance use treatment. ${ }^{33,34}$ However, there are limitations to the research studying tobacco cessation and substance use. Published studies of smoking cessation and substance use outcomes are set in treatment programs for dependence disorders. The studies of smokers with remote substance use are limited to recovering alcoholics. We are unaware of smoking cessation outcomes research studying individuals with a variety of substances used and with current and/or prior dependent and non-dependent use of substances to guide primary care of smoking cessation.

Furthermore, our analyses suggest that public health strategies, such as the California Tobacco Control Program, started in 1989 and focusing on changing population-wide social norms, knowledge, and public policy, ${ }^{35}$ may not have penetrated this demographic of women, as we did not find differences in cessation based upon the participants' state of residence. It may be important to determine how social marketing strategies may alter smoking acceptability among those with HIV risk. As we come to understand the importance of social networks on cessation, ${ }^{36}$ it is plausible that women who are HIV-infected or at risk are not part of social networks in which family members, friends, or co-workers have quit smoking. ${ }^{30}$

There are limitations to our findings. There were demographic and smoking-related differences between those with and without follow-up data, limiting the generalizability of the findings. The loss of follow-up is mostly due to the large number of women who had only a baseline study interview and secondarily due to women who died during the 10 years of follow-up. We had complete data on $89 \%$ of 841 surviving women with any follow-up data. Given that WHIS enrollees who were not included in this study were heavier and longer duration smokers, we believe that it is unlikely that women lost to follow-up had higher rates of sustained smoking cessation. Their loss to follow-up should not detract from our conclusion that HIV-infected and at-risk women have lower cessation rates than the US population. A second limitation of the study is that we used only baseline data as predictors of cessation. It is conceivable that there were time varying effects of variables that influenced cessation not captured by this analysis. We used only the year- 10 cessation as the outcome variable. There may have been some women who quit smoking for more than 12 months and subsequently relapsed who were classified in the group that did not achieve sustained cessation.

While we assessed having a usual source of medical care as a predictor of cessation and the WIHS study centers advised and encouraged cessation and referred all participants to primary care providers, in this analysis, we are unable to determine if medical care remained stable over time or if utilization affected cessation. This analysis covers the period of time immediately before and during the dissemination of HAART therapy. It is conceivable that simpler, contemporary HAART regimens may have changed the dynamic of smoking cessation among HIV-infected women in ways that we were unable to measure. Finally, there may be unmeasured mediators of cessation. ${ }^{31}$

The care of women with HIV and at risk for HIV is complex, with numerous medical, behavioral, and psychosocial dimensions related to their needs for substance use treatment, safe sex practices, stable housing, depression treatment, and medication adherence. It is possible that the low cessation rates reflect this difficult and competing set of needs for patients and their providers. While sustained cessation is lower among the women in WIHS than the general population, we do not know if they made fewer cessation attempts and if their cessation efforts were more likely to result in relapse. Future analyses using time varying longitudinal techniques, extending the analyses beyond the first 10 years of WIHS, and that assess short-term cessation and relapse are likely to help us understand the chain of events with respect to cessation in WIHS and define barriers to initiating and maintaining cessation.

Forty years after the first Surgeon General's report on smoking and health, ${ }^{37}$ there has been a multi-faceted antismoking campaign throughout the United States. We have witnessed the dissemination of clinical interventions, medications, and public health policies and programs that aid cessation. Among adult women, the rate of smoking declined from $34 \%$ in $1964^{38}$ to $17 \%$ in $2007 .{ }^{19}$ However, for women with and at high risk for HIV infection, the current rates of smoking dwarf those of US women in the 1960s, the smokingrelated risk are increased in the presence of HIV, and the rate of cessation among HIV-infected and at-risk women is well below that of the population at large. To avert predictable smoking-related morbidity and mortality, it is imperative that we intensify efforts to help these high-risk women quit smoking.

Acknowledgement: Data in this manuscript were collected by the Women's Interagency HIV Study (WIHS) Collaborative Study Group with centers (Principal Investigators) at New York City/Bronx Consortium (Kathryn Anastos); Brooklyn, NY (Howard Minkoff); Washington DC Metropolitan Consortium (Mary Young); The Connie Wofsy Study Consortium of Northern California (Ruth Greenblatt); Los Angeles County/Southern California Consortium (Alexandra Levine); Chicago Consortium (Mardge Cohen); Data Coordinating Center (Stephen Gange). The WIHS is funded by the National Institute of Allergy and Infectious Diseases (UO1-AI-35004, UO1AI-31834, UO1-AI-34994, UO1-AI-34989, UO1-AI-34993, and UO1- 
AI-42590) and by the National Institute of Child Health and Human Development (UO1-HD-32632). The study is co-funded by the National Cancer Institute, the National Institute on Drug Abuse, and the National Institute on Deafness and Other Communication Disorders. Funding is also provided by the National Center for Research Resources (UCSF-CTSI grant number UL1 RRO24131). The contents of this publication are solely the responsibility of the authors and do not necessarily represent the official views of the National Institutes of Health.

The authors wish to thank Sally Urwin for her support of this analysis.

Conflicts of Interest: The authors report no conflicts of interest.

Corresponding Author: David Goldberg, MD, Division of General Medicine, John H. Stroger, Jr Hospital of Cook County and Rush University, $1901 \mathrm{~W}$ Harrison Street, 9th Floor, Administrative Building, Chicago, IL 60612, USA (e-mail: david_goldberg@rush. edu).

\section{REFERENCES}

1. Niaura R, Shadel WG, Morrow Ktashima K, Flanigan T, Abrams DB. Human immunodeficiency virus infection, AIDS, and smoking cessation: the time is now. Clin Inf Dis. 2000;31:808-12.

2. Gritz ER, Vidrine DJ, Fingeret MC. Smoking cessation: a critical component of medical management of chronic disease populations. Am J Prev Med. 2007;33(Suppl):S414-22.

3. Webb M, Vanable PA, Carey MP, Blair D. Cigarette smoking among HIV+ men and women: examining health, substance use, and psychosocial correlates across the smoking spectrum. J Behav Med. 30:371-83.

4. Palella FJ, Delaney KM, Moorman AC, et al. Declining morbidity and mortality among patients with advanced human immunodeficiency virus infection. N Engl J Med. 1998;338:853-60.

5. Mocroft A, Vella S, Benfield TL, et al. Changing patterns of mortality across Europe in patients infected with HIV-1. Lancet. 1998;352:172530 .

6. Nahvi S, Cooperman NA. Review: the need for smoking cessation among HIV-positive smokers. AIDS Educ Prev. 2009;21(Suppl A):14-27.

7. Feldman JG, Minkoff $\mathbf{H}$, Schneider MF, et al. Association of cigarette smoking with HIV prognosis among in the HAART era: a report from the women's interagency HIV study. Am J Pub Health. 2006;96:1060-5.

8. Turner J, Page-Shafer K, Chin DP. Adverse impact of cigarette smoking on dimensions of health-related quality of life in persons with HIV infection. AIDS Pat Care STDS. 2001;15:615-24.

9. Crothers K, Griffith TA, McGinnin KA, et al. The impact cigarette smoking on mortality, quality of life, and comorbid illness among HIVpositive veterans. J Gen Intern Med. 2005;20:1142-5.

10. Depairon M, Chessex S, Sudre $\mathbf{P}$, et al. Premature atherosclerosis in HIV-infected individuals - focus on protease inhibitor therapy. AIDS. 2001;15:329-34.

11. DAD Study Group. Class of antiretroviral drugs and the risk of myocardial infarction. N Engl J Med. 2007;356:1723-35.

12. Grinspoon S, Carr A. Cardiovascular risk and body fat abnormalities in HIV-infected adults. N Engl J Med. 2005;352:48-62.

13. Kirk GD, Merlo C, O'Driscoll P, et al. HIV infection is associated with an increased risk for lung cancer, independent of smoking. Clin Inf Dis. 2007;45:103-10.

14. Wistuba II, Behrens C, Milchgrub S, et al. Comparisons of molecular changes in lung cancers in HIV-positive and HIV-indeterminate subjects. JAMA. 1998;279:1554-9.

15. Crothers K, Butt AA, Gilbert CL, Rodiriguz-Barradas MC, Crystal S, Justice AM. Increase COPD among HIV-positive compared to HIVnegative veterans. Chest. 2006;130:1326-33.
16. Burkhalter JE, Springer CM, Chhabra R, Ostroff JS, Rapkin BD. Tobacco use and readiness to quit smoking in low income HIV-infected persons. Nic Tob Res. 2005;7:511-22.

17. Gritz ER, Vidrine DJ, Lazev AB, Amick BC, Arduino RC. Smoking behavior in a low-income multi-ethnic HIV/AIDS population. Nic Tob Res. 2004;7:71-7.

18. Tesorero JM, Giervic SM, Carrascal A, Lavigne HE. Smoking among HIV positive New Yorkers: prevalence, frequency, and opportunities for cessation. AIDS Behav. 2008;Epub Sept 7.

19. CDC. Cigarette smoking among adults — United States 2007. MMWR 2008;57:1221-6.

20. Messer K, Pierce JR, Shu-Hong Z, et al. The California Tobacco Control Program's effect on adult smokers: (1) smoking cessation. Tob Control. 2007; 16:85-90.

21. Messer K, Trinidad DR, Al-Delaimy WK, Pierce JR. Smoking cessation rates in the United States: a comparison of young adult and older smokers. Am J Pub Health. 2008;98:317-22.

22. Minkoff H, Feldman JG, Strickler HD, et al. Relationship between smoking and human papillomavirus infections in HIV-infected and uninfected women. J Infect Dis. 2004;189:1821-8.

23. Barkan SE, Melnick SL, Preston-Martin S, et al. The Women's Interagency HIV Study. Epidemiology. 1998;9:117-25.

24. Vidrine DJ. Cigarette smoking and HIV/AIDS: health implications, smoker characteristics and cessation strategies. AIDS Educ Prev. 2009;21(Suppl A):3-13

25. Pierce JP, Gilpin EA. A minimum 6-month prolonged abstinence should be required for evaluating smoking cessation trials. Nic Tob Res. 2003;5:151-3.

26. Gilpin EA, Pierce JP, Farkas AJ. Duration of smoking abstinence and success in quitting. J Nat Cancer Inst. 1997;89:572-6.

27. Mamary EM, Bahrs D, Martinez S. Cigarette smoking and the desire to quit among individuals living with HIV. AIDS Pat Care STDs. 2002; 16:39-42

28. Lloyd-Richardson EE, Stanton CA, Papandonatos GD, et al. HIVpositive smokers conseidering quitting: differences by race/ethnicity. Am J Health Behav. 2008;32:3-15.

29. Barbeau EM, Krieger N, Soobader MJ. Working class matters: socioeconomic disadvantage, race/ethnicity, gender, and smoking in NHIS 2000. Am J Public Health. 2004;94:269-78.

30. Humfleet GL, Delucchi K, Kelley K, Hall SM, Dilley J, Harrison G. Characteristics of HIV-positive cigarette smokers: a sample of smokers facing multiple challenges. AIDS Educ Prev. 2009;21(Suppl A):54-64.

31. Stanton CA, Lloyd-Richardson EE, Papandonatos GD, de Dios MA, Niaura R. Mediators of the relationship between nicotine replacement therapy and smoking abstinence among people living with HIV/AIDS. AIDS Educ Prev. 2009;21(Suppl A):65-80.

32. Stevens PE, Keigher SM. Systematic barriers to health care access for U.S. women with HIV: the role of cost and insurance. Inter J Health Serv. 2009;39:225-43.

33. Prochaska JJ, Delucchi K, Hall SM. A meta-analysis of smoking cessation interventions with individuals in substance abuse treatment or recovery. J Counsel Clin Psychol. 2004;72:1144-56.

34. Hall SM. Nicotine interventions with comorbid populations. Am J Prev Med. 2007;33(Suppl):S406-13.

35. Pierce JP, Gilpin EA, Emery SL. Has the California tobacco control program reduced smoking? JAMA. 1998;280:893-9.

36. Christakis NA, Fowler JH. The collective dynamics of smoking in a large social network. N Engl J Med. 2008;358:2249-58.

37. Smoking and Health. Report of the Advisory Committee to the Surgeon General of the Public Health Service. U.S. Department of Health, Education, and Welfare, Public Health Service, Communicable Disease Center, 1964

38. Women and Smoking: a report of the Surgeon General. Washington: US Dept of Health and Human Services, Public Health Service, Office of the Surgeon General; 2001. 